\title{
SINTER-FORGING OF A GRADED MMC WEAR COMPONENT
}

\author{
Bernd-Arno BEHRENS, Martin BONHAGE, Jonathan URSINUS \\ Institute of Forming Technology and Machines (IFUM), Leibniz Universität Hannover, Garbsen, Germany, \\ EU, ursinus@ifum.uni-hannover.de, bonhage@ifum.uni-hannover.de, behrens@ifum.uni-hannover.de \\ https://doi.org/10.37904/metal.2019.710
}

\begin{abstract}
Metal Matrix Composites (MMC) combined with the concept of Functionally Graded Materials (FGM) offer potential to adjust the material properties based on the local load conditions. In this study, a sinter-forging process was deployed to produce an MMC wear component, consisting of a steel matrix and Fused Tungsten Carbide (FTC) particles, for later use in a hot forging tool. A low alloyed carbon steel powder and a high-speed steel powder (similar to HS 6-5-2) were processed. A graded hard phase concentration was generated by stacking layers of increasing hard phase concentration (max. $10 \mathrm{vol} . \%$ ), before the pressing of the powder specimens. After pressing, the specimens were sintered and then forged to near full density. Metallographic imaging was used to display the hard phase gradient and to identify the microstructure of the components. The dissolution of the tungsten carbides during sintering was also investigated by Scanning Electron Microscopy (SEM) and Energy Dispersive X-ray spectroscopy (EDX). The sinter-forged components showed a dense microstructure with embedded hard phases. The introduced gradient structure was not altered by the forging operation and the components seem promising for the planned use as a wear component in hot forming tools.
\end{abstract}

Keywords: Sinter-forging, metal matrix composites, functionally graded materials, powder metallurgy

\section{INTRODUCTION}

In highly productive forging processes, the tooling lifespan can have a significant impact on the economic performance of the forging lines. Especially in hot forming operations, the forging dies suffer under a combination of different wear mechanisms. The high surface temperatures promote plastic deformation of the tool surface and abrasion due to lowered hardness. In combination with spray lubrication and cooling, the tool steels undergo cyclic temperature changes and therefore need adequate thermal shock resistance.

Carefully designed forging dies generally withstand the pure mechanical loads, but wear is always present and limits the tool's lifespan. Different methods can be employed to create very hard surface layers on the forging dies and thus increase wear resistance. Nitriding of the base material is often a first step and can be combined with surface coatings [1,2]. This process creates thin, ceramic layers which are considerably harder than most abrasives. However, because of the sudden change in properties between the ceramic coating and the metal base material, fatigue under cyclic temperature changes might occur.

Another promising idea is the use of Metal Matrix Composites (MMC). These have been successfully examined for application in ground transportation and mineral handling [3,4]. They offer increased resistance against grooving wear without the need for a fully ceramic layer. Consisting of a metal matrix reinforced with ceramic particles, the properties of MMC for wear applications can be tuned by material choice, hard phase concentration, size or shape of the reinforcing particles [5]. This allows for an adjustment of the local material properties based on the stress or wear regime and the production of Functionally Graded Materials (FGM). Graded MMC components promise potential to increase the wear resistance of hot forming tools, while reducing sudden property changes by introducing a gradient to the MMC composition.

Several process routes are used for the production of MMC. Among these the most prominent example is the melt-metallurgy [6]. Either the hard phase particles are stirred into the liquid metal or a porous inlay is infiltrated 
by the melt. Poor wettability of common ceramics, agglomeration of particles and low chemical stability of the hard phase are typical problems associated with this route $[7,8]$. The powder metallurgy (PM) offers an alternative. Hard phase particles are mixed with a matrix powder and then consolidated using pressing and sintering, hot isostatic pressing (HIP), powder extrusion or sinter forging. During processing, segregation of the mixed powders may occur and has to be controlled. Although, this segregation also offers a possibility to produce continuously graded materials [9]. Many studies on wear resistant, steel based MMC use a PM route [10]. Common matrix materials include cold and hot work tool steels as well as high-speed steels. Different oxides and carbides are tested as a ceramic hard phase [5].

In this work, MMC are produced via a PM route to serve as wear components in future studies that test them in a hot forging process. The PM route brings the advantage of a free design of the hard phase concentration gradient towards the tools work surface. To achieve the mechanical properties necessary to bear the forging loads, the MMC components need to achieve maximum density. Therefore, a sinter forging process is employed which serves as an alternative to the common hot isostatic pressing (HIP) for the full densification of powders.

\section{EXPERIMENTAL}

To produce MMC components with a steel matrix and ceramic hard phases a sinter-forging process was developed and tested. A low alloyed Steel (LAS) powder Atomet 1001 (Rio Tinto, Canada) and highly alloyed high-speed steel (HSS) powder PX M2/04 (Höganäs Ltd., UK) were used. The LAS powder is a press-ready mix of water-atomised iron powder, $0.7 \%$ graphite and $0.75 \mathrm{wt}$ \% lubrication agent (ZnSt). The HSS powder is prealloyed and water-atomised. The particle size distributions of both powders are given in Table 1. The chemical composition of the mentioned steel powders is given in Table 2. The powders were mixed with Fused Tungsten Carbide (FTC) particles (63-180 $\mu \mathrm{m})$ in a Turbula powder mixer and then pressed, sintered and hot forged.

Table 1 Particle size distributions of the used steel powders

\begin{tabular}{|c|c|c|c|}
\hline & $>\mathbf{0} \boldsymbol{\mu m}$ & $\mathbf{> 5 0} \boldsymbol{\mu m}$ & $>\mathbf{1 0 0} \boldsymbol{\mu m}$ \\
\hline HSS & $6.2 \%$ & $15.0 \%$ & $78.7 \%$ \\
\hline LAS & $14.1 \%$ & $48.4 \%$ & $37.5 \%$ \\
\hline
\end{tabular}

The concept of the production process is summarized in Figure 1. The powders were arranged in six layers of equal height and increasing carbide content. The top layer had no carbides while the bottom layer contained 10 vol.\% FTC (DEW, Germany). Specimens with a diameter of $36 \mathrm{~mm}$ and a height of $38 \mathrm{~mm}$ were pressed using a hydraulic powder press (SMS Meer, Germany). Controlled movement of the die ensured equal pressure on both the upper and lower punch. The compaction pressures were about $560 \mathrm{MPa}$ for HSS and about $600 \mathrm{MPa}$ for LAS.

Table 2 Nominal chemical composition of the use used steel powders in wt.\% (specified by the manufacturer)

\begin{tabular}{|c|c|c|c|c|c|c|c|c|c|c|}
\hline & C & Co & Cr & Cu & Mn & Mo & Ni & V & W & Fe \\
\hline HSS & 0.79 & 0.20 & 4.40 & 0.13 & 0.32 & 5.22 & 0.27 & 1.87 & 6.54 & Balance \\
\hline LAS & 0.7 & - & - & - & 0.18 & - & - & - & - & Balance \\
\hline
\end{tabular}

The green compacts were sintered in a vacuum furnace (Xerion, Germany) with matrix specific temperature regimes. While the LAS was held for $30 \mathrm{~min}$ at $1120^{\circ} \mathrm{C}$, higher sintering temperatures for HSS were chosen based on a study by Eroglu [11]. A sintering temperature of $1250{ }^{\circ} \mathrm{C}$ led to a rapid dissolution of the FTC particles in the HSS matrix. Therefore, the sintering temperature of the HSS specimen was reduced to $1200^{\circ} \mathrm{C}$ 
and the holding time was reduced to $5 \mathrm{~min}$. Both powders were delubricated at $600{ }^{\circ} \mathrm{C}$ for $15 \mathrm{~min}$. The heating rate was approximately $5 \mathrm{~K} / \mathrm{min}$. After sintering, the specimens were cooled slowly in the oven. For final densification, they were then heated under a protective atmosphere to $1100{ }^{\circ} \mathrm{C}$ and calibrated in a sinterforging tool. A screw press (LASCO, Germany) with $40 \mathrm{~kJ}$ of nominal energy was used for the sinter-forging. The cylinders were densified with minimal material flow to preserve the structure of the FTC gradient. A thin flash geometry caused high compacting pressures, while allowing for deviations in the part volume. The specimens were air-cooled after forging. Forged and sintered specimens were wire cut, polished and examined using micrographs. Hardness values HV 30 were measured along their height. The dissolution of FTC particles was investigated by Scanning Electron Microscopy (SEM) and the element concentrations were measured using Energy Dispersive X-ray Spectroscopy (EDX). The density of the pressed cylinders was calculated using their geometric data and weight, while the density of the forged specimen was measured using the Archimedes' principle.

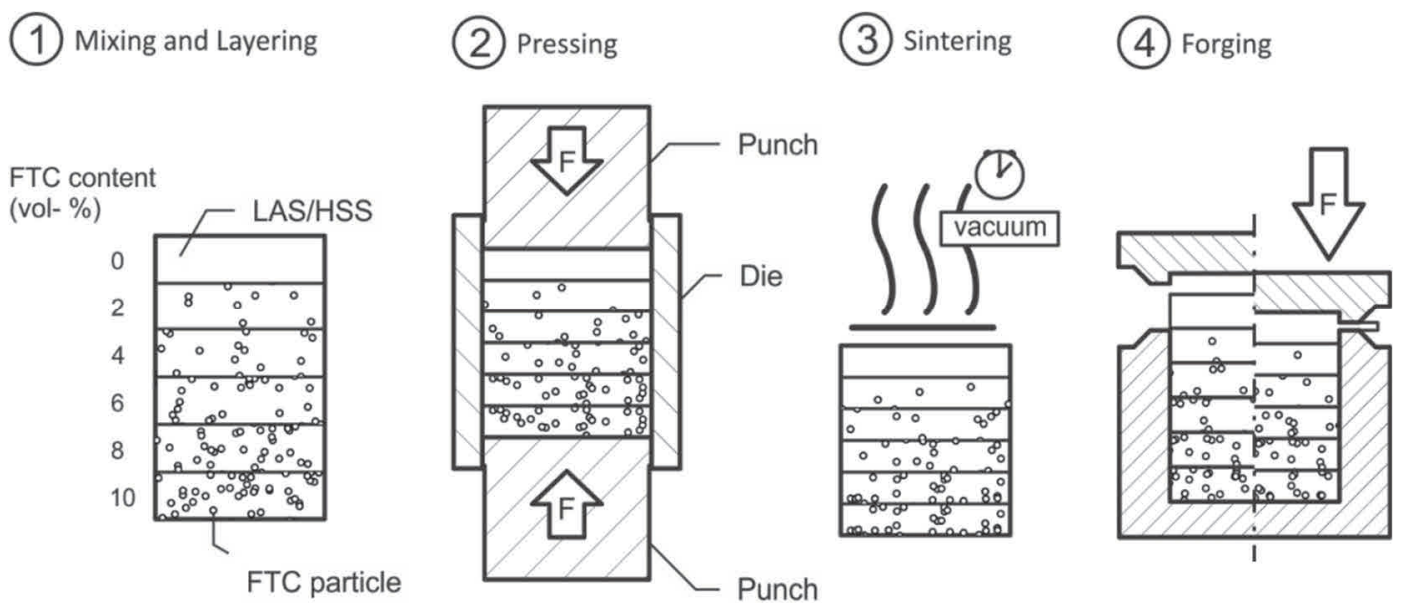

Figure 1 Overview of the sinter forging process of graded MMC specimens

\section{RESULTS}

\subsection{Dissolution of FTC particles}

When sintering the HSS based MMC at $1250{ }^{\circ} \mathrm{C}$, the FTC particles dissolved and formed new phases rich in carbon and tungsten (Figure 2). These regions were more closely examined by EDX. The measured composition of those phases is shown in Table 3.

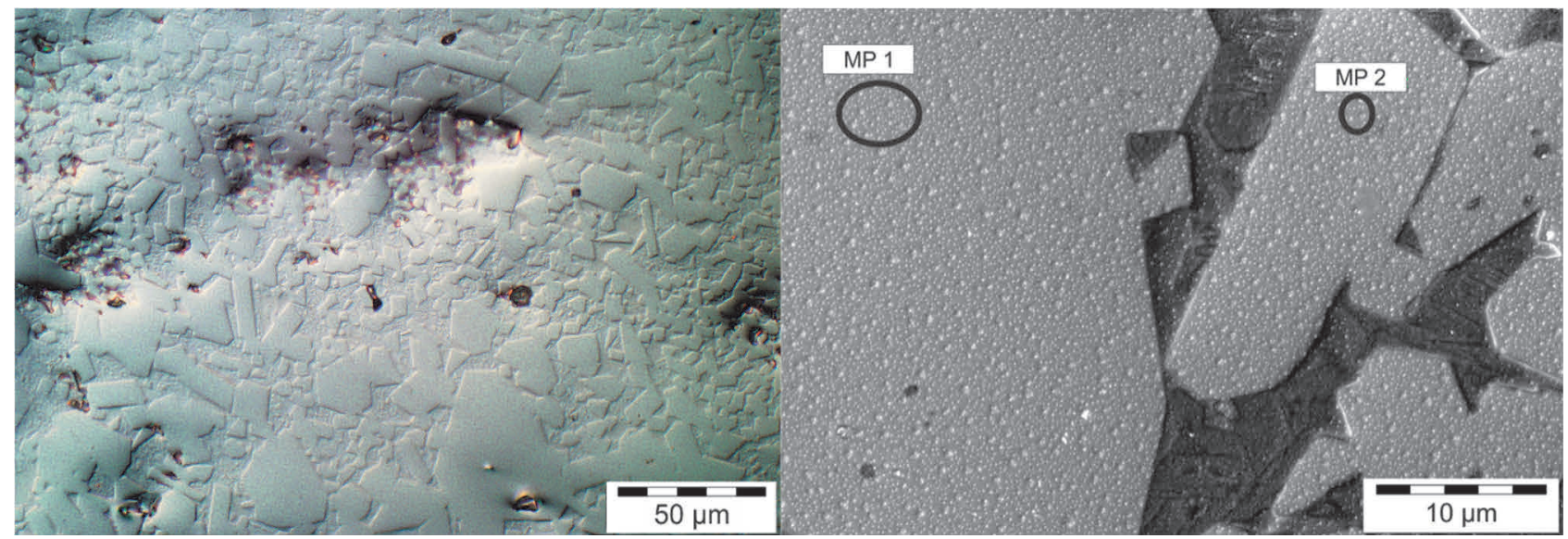

Figure 2 Dissolved WC phases under stereo lighting (left); SEM micrograph and measuring points (MP) for the EDX analysis (right) 
Table 3 Composition of the newly formed phases in at. \% as measured by EDX

\begin{tabular}{|l|l|l|l|l|l|l|l|}
\hline & C & O & V & Cr & Mn & Fe & W \\
\hline MP1 & 29.7 & 0 & 1.7 & 2.4 & 0.2 & 38.0 & 28.0 \\
\hline MP2 & 30.0 & 0 & 2.1 & 2.6 & 0.2 & 39.2 & 25.8 \\
\hline
\end{tabular}

\subsection{Density}

The sintering process showed no significant influence on part geometry. Weight losses were only recognised for the LAS powder. These made up $1 \%$ of the part's total weight and represented the burning of the lubricant. The HSS specimen did not show significant weight loss. Therefore, an insufficient burn out of the lubricant might be expected.

A comparison of the achieved mean densities of forged parts with their density after pressing is given in Table 4. The aforementioned incomplete burn out of the lubricant shows in the slightly lower density values for the HSS specimens, while the densities for the LAS indicate a full densification.

Table 4 Measured mean density of the produced specimen after pressing and after sinter-forging

\begin{tabular}{|c|c|c|}
\hline & Mean Density after pressing $\mathbf{( g / \mathbf { c m } ^ { 3 } )}$ & Mean Density after sinter-forging $\left(\mathbf{g} / \mathbf{c m}^{\mathbf{3}}\right)$ \\
\hline HSS & 5.7 & 7.79 \\
\hline LAS & 6.6 & 7.86 \\
\hline HSS + FTC & 6.4 & 8.32 \\
\hline LAS + FTC & 7.3 & 8.23 \\
\hline
\end{tabular}

\subsection{Microstructure}

Metallographic examinations of the produced MMC specimen show a compact matrix with minimal porosity and the FTC particles embedded in it (Figure 3). Oxides were observed near the surfaces. As the components will be machined to their final geometry, these layers can easily be removed. The hard phase concentration gradient is shown on the right in Figure 4. The image was taken under stereo lighting and contrast has been increased to highlight the dark hard phase particles.
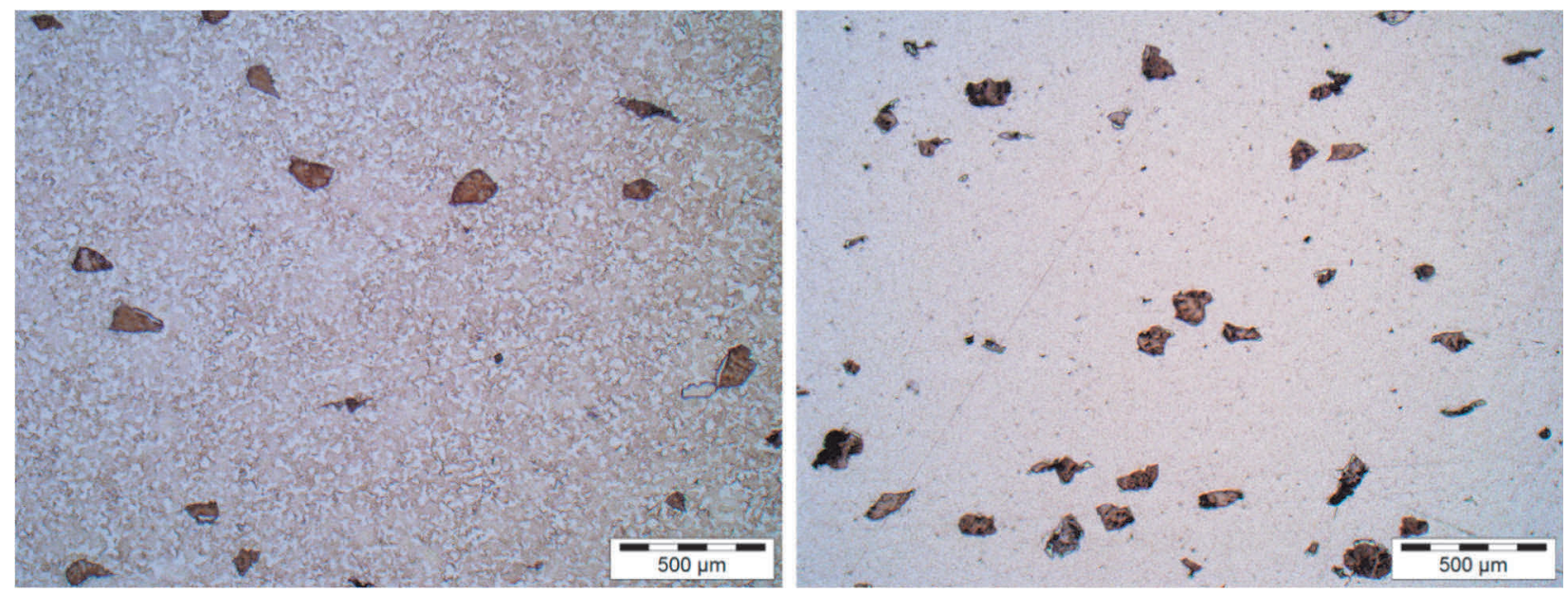

Figure 3 Metallographic images the FTC particle in LAS matrix (left) and HSS matrix (right) after sinter-

\subsection{Hardness} forging

Macro hardness measurements were taken along the height of the forged MMC specimens. The results are shown in the graph in Figure 4. The hardness profile shows no significant influence of the hard phase 
concentration on the measured LAS macro hardness values. The HSS shows a small hardness gradient. But comparisons with the hardness profile after sintering propose that this is due to different cooling rates after sinter-forging. The HSS specimens are hardened during the air-cooling after the forging step, which explains the high hardness of those specimens. For the LAS the hardness was under $250 \mathrm{HV} 30$ at all points.
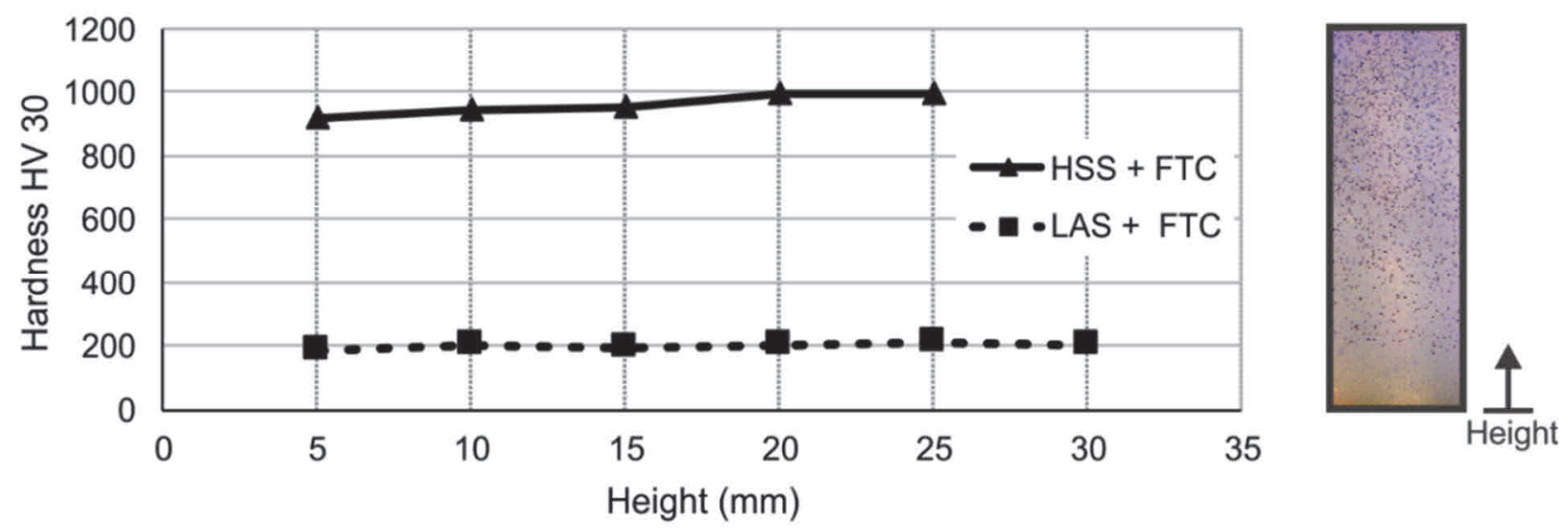

Figure 4 Macro hardness of the produced MMC specimen

\section{DISCUSSION}

\subsection{Dissolution of FTC}

Mixed carbides of iron and tungsten form following the composition $\mathrm{Fe}_{3} \mathrm{~W}_{3} \mathrm{C}$ [12] and were observed in similar studies in diffusion seams along FTC particles $[13,14]$. This explains the high carbon and tungsten content at the measuring points. The dissolution of the hard phases limits the sintering temperatures to under $1250^{\circ} \mathrm{C}$ and might be accelerated by the formation of liquid phases. This excludes liquid phase sintering (LPS) from the viable sintering regimes, which is regularly used in the processing of highly alloyed steels. If high density is a requirement, HIP or sinter-forging is beneficial, as conventional sintering with moderate temperatures has proven problematic for high alloy steel powders.

\subsection{Sinter-Forging}

The density measurements and metallographic examinations indicate a near full densification by the hot calibration step. However, the incomplete burn out of the micro wax in the HSS specimens has to be addressed in further studies. Nevertheless, no indication for a negative influence on the microstructure could be identified. The hard phase concentration gradient visible in Figure 4 shows no distinctively layered structure. The concentration steadily increases from top to bottom and therefore sudden changes in the material properties are avoided, while reinforcing the working surface of the component. The gradient was not altered by the hot calibration step. For further studies, the presented sinter-forging process is able to produce a variation of MMC components with different steel matrix materials or concentration gradients.

\subsection{Hardness Profile}

The measured macro hardness profile shows the importance of matrix material properties in MMC as these determine the overall resistance to indentation, at least with low hard phase contents. The results are in good agreement with the data reported by Theisen and Packeisen. In a study on FTC reinforced tool steel the reported hardness HV 125 was mostly independent from the hard phase concentration. It correlated directly with the chosen annealing temperature during heat treatment [13]. This is an indication, that later performance of the MMC as a forging tool component is dependent on matrix hardness and therefore adequate material selection and heat treatment has to be further investigated. 


\section{CONCLUSION}

The production of a graded MMC by sinter-forging was investigated. It was shown, that the process is able to produce MMC materials from different steel matrix powders. Subsequent sinter-forging of the compacts could compensate differences in press density and sintering behaviour and produce near fully dense components. Metallographic examination, as well as hardness testing indicated usability of the components for further investigations, regarding their performance in hot forming tools. An upper temperature limit for sintering FTC reinforced Fe-based MMC was found to be below $1250^{\circ} \mathrm{C}$.

\section{ACKNOWLEDGEMENTS}

The presented results are based on the research project "Development of a wear resistant and stress adapted modular forming tool, manufactured out of a ceramics reinforced metal matrix composite material (MMC), for the use in hot forging industry", Project number 312033221. The authors would like to thank the German Research Foundation (DFG) for the financial support.

\section{REFERENCES}

[1] BEHRENS, B.-A., LIPPOLD, L., PUPPA, J., HÜBSCH, C., LANGEN, D. and MÖHWALD, K. Increasing the wear resistance of hot forging dies by PVD-deposited, titanium-based hard coatings. Forschung im Ingenieurwesen. 2017. vol. 81, no. 1, pp. 1-12.

[2] BEHRENS, B.-A., BOUGUECHA, A., HUSKIC, A., BAUMER, M., PASCHKE, H. and LIPPOLD, L. Increasing the Efficiency of Forging Operations Using Adjusted Tribological Surfaces Enhanced by Hard Coatings. Tribology Online.2016, vol. 11, no. 2, pp. 432-443.

[3] CHAWLA, N. and CHAWLA, K.K. Metal-matrix composites in ground transportation. JOM. 2006, vol. 58, no. 11, pp. 67-70.

[4] BERNS, H. Comparison of wear resistant MMC and white cast iron. Wear. 2003. vol. 254, no. 1-2, pp. 47-54.

[5] BERNS, H. Hartlegierungen und Hartverbundwerkstoffe. 1st. ed. Berlin: Heidelberg: Springer Berlin Heidelberg, 1998. p. 322.

[6] KAINER, K.U. Basics of Metal Matrix Composites, In: Kainer, K.U., ed. Metal Matrix Composites. Weinheim, FRG: Wiley-VCH Verlag GmbH \& Co. KGaA, 2006, pp. 1-54.

[7] HASHIM, J., LOONEY, L. and HASHMI, M.S.J. Metal matrix composites: production by the stir casting method. Journal of Materials Processing Technology. 1999. vol. 92-93, pp. 1-7.

[8] MIRACLE, D. Metal matrix composites - From science to technological significance. Composites Science and Technology. 2005. vol. 65, no. 15-16, pp. 2526-2540.

[9] BEHRENS, B.-A. and BOHR, D. Manufacturing of functionally graded metal matrix composite materials by segregation. International Journal of Materials Research. 2018. vol. 109, no. 5, pp. 373-380.

[10] L.A. Dobrzański, KLOC-PTASZNA, A., DYBOWSKA, A., MATULA, G., GORDO, E. and TORRALBA, J.M. Effect of WC concentration on structure and properties of the gradient tool materials. Journal of Achievements in Materials and Manufacturing Engineering. 2007. vol. 20, no. 1-2, pp. 91-94.

[11] EROGLU, S. Sintering and Mechanical Properties of AISI M2 High-Speed Steel Powder Molded at Low Pressures. Materials and Manufacturing Processes. 2010. vol. 25, no. 9, pp. 1025-1029.

[12] RAPATZ, F. Die Edelstähle. 1st.ed. Berlin, Heidelberg: Springer Berlin Heidelberg, 1934. p. 1047.

[13] THEISEN, W. and PACKEISEN, A. Abrasion Behaviour of Hard Phase Containing Fe-Base Alloys. Materialwissenschaft und Werkstofftechnik. 2004. vol. 35, no. 10-11, pp. 736-740.

[14] WEBER, S. and THEISEN, W. Sintering of High Wear Resistant Metal Matrix Composites. Advanced Engineering Materials. 2007. vol. 9, no. 3, pp. 165-170. 